\title{
Are Patients with Coronavirus Disease 2019 and Obesity at a Higher Risk of Hospital and Intensive Care Unit Admissions? A Systematic Review and Meta-analysis
}

\author{
Anggi Lukman Wicaksana ${ }^{1,2 *}$, Nuzul Sri Hertanti ${ }^{3}$, ${ }^{(1)}$ Raden Bowo Pramono ${ }^{4,5}$, Yu-Yun Hsu ${ }^{6}$ \\ ${ }^{1}$ Department of Medical Surgical Nursing, Universitas Gadjah Mada, Yogyakarta, Indonesia; ${ }^{2}$ The Sleman Health and \\ Demographic Surveillance System, Universitas Gadjah Mada, Yogyakarta, Indonesia; ${ }^{3}$ Center for Tropical Medicine, Universitas \\ Gadjah Mada, Yogyakarta, Indonesia; ${ }^{4}$ Department of Internal Medicine, Universitas Gadjah Mada, Yogyakarta, Indonesia; \\ ${ }^{5}$ Department of Internal Medicine, Dr. Sardjito General Hospital, Yogyakarta, Indonesia; ${ }^{6}$ Department of Nursing, National \\ Cheng Kung University, Tainan, Taiwan, Republic of China
}

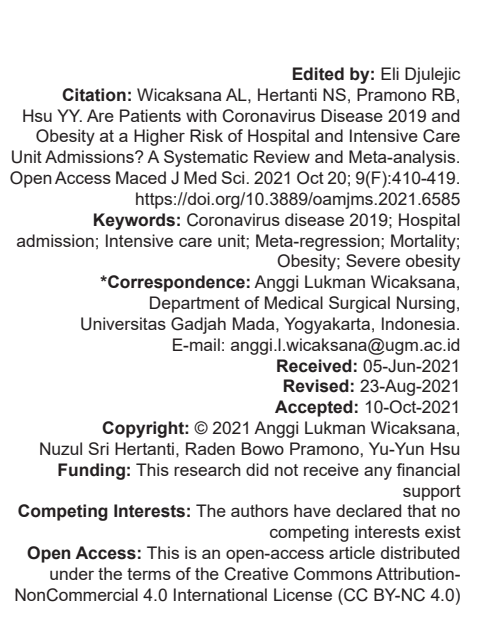

Abstract

BACKGROUND: Obesity, common condition among patients with coronavirus disease 2019 (COVID-19), contributes to illness severity during hospitalization. To date, knowledge on the prevalence, risk of hospital and intensive care units (ICU) admissions and mortality is limited. Therefore, systematic review and meta-analysis were conducted using a preferred reporting items for systematic reviews and meta-analyses guideline.

AIM: The study aimed to address the prevalence, risk of hospital and ICU admissions and mortality among patients with COVID-19 and obesity.

METHODS: The Newcastle-Ottawa scale was used to assess the quality of a study. Primary outcomes were the prevalence and risk of hospitalization, and secondary outcomes were the risk of ICU admissions and mortality risk. Mantel-Haenszel with random effects was applied, and the effect measure was odds ratio (OR) with $95 \%$ confidence interval $(\mathrm{Cl})$.

RESULTS: Nine studies were included in the systematic review, and only four studies for meta-analysis. Among 29,776 patients with COVID-19, obesity was identified as the second-highest comorbidity. The prevalence rates of obesity and severe obesity among patients with COVID-19 were $26.1 \%$ and $15.5 \%$, respectively. Obesity resulted in significantly increased risk of hospital admission $(O R=1.99,95 \% \mathrm{Cl}=1.12-3.53, \mathrm{p}=0.02)$ and ICU admission $(\mathrm{OR}=1.77,95 \%=\mathrm{Cl} 1.52-2.06, \mathrm{p}<0.00001)$. Severe obesity had a significantly increased risk of ICU admission $(\mathrm{OR}=1.79,95 \% \mathrm{Cl}=1.42-2.25, \mathrm{p}<0.00001)$. The mortality rate of patients with COVID-19 and obesity was about $30.5 \%(438 / 1,434)$, and $19.7 \%(2,777 / 14,095)$ of them recovered from COVID-19.

CONCLUSION: Obesity poses as nearly twice the risk of hospital and ICU admissions, and severe obesity contributes to almost twice the risk of ICU admissions.

\section{Introduction}

Chronic diseases, such as hypertension, diabetes, heart, and pulmonary diseases, have been recognized and associated with the severity of coronavirus disease 2019 (COVID-19) [1], [2], [3]. Among all chronic conditions, obesity has been seldom identified as a risk factor of COVID-19 [3], [4], [5], [6]. The previous studies identified that obesity or the body mass index (BMI) is equal to or more than 30 , was major risk factor for the severity of COVID- 19 [1], [7], [8]. The prevalence rate of obesity among patients with COVID-19 varies. Bello-Chavolla et al. [1] reported $20.7 \%$ patients with COVID-19 and obesity, whereas Richardson et al. [9] reported $41.7 \%$ patients with COVID- 19 and obesity. Other studies have also reported a different prevalence rate of obesity from $26.8 \%$ to $47.5 \%$ among patients COVID- 19 [2], [10], [11]. To date, COVID- 19 is spreading worldwide, especially in areas where obesity is mostly dominant, such as North American and European countries [3].

Obesity in patients with COVID-19 is associated with adverse outcomes [1], [12], [13] and affects patients' outcomes [2], [3], [7], [10], [11]. Patients with severe COVID-19 and obesity require more hospitalization [10], and some of them even need intensive care because of the nature of disease progression [3], [5], [7], [10], [12]. Furthermore, obesity contributes to the occupation of invasive mechanical ventilation [2], [3] and increases the risk of mortality of patients with COVID-19 [1], [13].

The effect of obesity on patients with COVID- 19 should be explored [3]. Health-care providers and policy makers must identify the risk level and outcomes related to COVID-19 [11]. However, the previous studies were limited in terms of particular areas/countries and number of participants, resulting in 
a wide range of outcomes of the risk level and causing difficulty in decision-making.

A systematic review and meta-analysis to identify the prevalence of obesity, the risk of hospital and intensive care unit (ICU) admissions, and the mortality risk among patients with COVID-19 and obesity and severe obesity, was conducted. The study aimed to address the following questions: (a) Are patients with COVID-19, obesity, and severe obesity at a high risk of hospital admissions? (b) Are patients with COVID-19, obesity, and severe obesity at a high risk of ICU admissions? (c) Are patients with COVID-19, obesity, and severe obesity at a high risk of mortality?

\section{Methods}

The systematic review and meta-analysis study were conducted and the guideline of the preferred reporting items for systematic reviews and meta-analyses (PRISMA) protocol [14] was applied for selecting the articles.

\section{Eligibility criteria}

The prevalence and risk of hospital admissions were determined as the primary outcomes, and the risk of ICU admission and mortality risk was identified as the secondary outcomes. The study design was limited to prospective and retrospective cohort or case control studies. Only published articles in 2020 and written in English were included in the study. The preprint articles did not included to minimize the bias and only peer-reviewed articles were involved. The targeted populations were classified as (1) all patients with COVID-19 and obesity (BMI $\geq 30$ ) and (2) those who had COVID-19 and severe obesity (BMI $\geq 35$ ). Commentaries, abstracts, news, editorials, and case reports were excluded from the study.

\section{Search strategy}

Science Direct, PubMed, Clinical Keys, and Google Scholar databases were used with two authors (N.S.H. and A.L.W.) were independently searched. Any different findings were communicated and consulted to the third author (R.B.P.). The medical subject heading (MeSH) terms ("COVID-19" OR "severe acute respiratory syndrome coronavirus 2") AND "Obesity" AND "Hospital Admission" were used in all the databases from January 1, 2020, to May 10, 2020. Researchers searched and used MeSH terms in PubMed as standard terms, and then the terms were used in other databases to make sure the systematic search. The MeSH terms represent biomedical concepts in particular context as assigned label. Articles were selected using the Microsoft Excel spreadsheet and extracted by two authors (N.S.H. and A.L.W.). All the studies that fitted the inclusion criteria were included in the systematic review. From each study, following data were extracted as the number of patients COVID-19; median age; number of males; prevalence of obesity, diabetes, and hypertension; number of hospitalized patients with COVID-19; number of patients who suffered from COVID-19 and were admitted to the ICU; and number of survivors or nonsurvivors. Obesity $(\mathrm{BMI} \geq 30)$ and severe obesity $(\mathrm{BMI} \geq 35)$ were identified when data were available for comparison.

\section{Risk of bias assessment}

Newcastle-Ottawa quality assessment scale (NOS) was used to assess the quality of nonrandomized studies in meta-analysis. The NOS was available for case control and cohort studies [15]. For this review, scoring outcomes were classified into three categories, that is, low ( $<5$ stars), moderate (5-7 stars), and high quality (more than 7 stars) [16]. Only studies with at least five stars (moderate level) were analyzed. Funnel plots and Egger's regression test was utilized to assess publication bias. The publication bias was identified when the studies were asymmetrically distributed or when their concentration at the bottom of the funnel plots was high [17]. Egger's regression test was performed to detect the asymmetry of the funnel plots. The absence of a significant outcome indicated there is no bias on the selected studies [18].

\section{Data synthesis and analysis}

Data were examined using Review Manager 5.3 [19] and comprehensive meta-analysis (CMA) version 3.0 (trial) [20]. The extracted data were classified into primary and secondary outcomes. They were assembled using the random effects of the Mantel- Haenszel model with OR as the effect measure with $95 \% \mathrm{Cl}$. The Higgins I ${ }^{2}$ statistic was utilized to check the heterogeneity among groups [21]. The heterogeneity outcomes were classified into low, moderate, and high when the $\mathrm{I}^{2}$ was less than $25 \%, 25-75 \%$, and more than $75 \%$, respectively [16], [22]. Meta-regression with random effect was carried out to explore heterogeneity if the dataset was unavailable to run a sub-group analysis [23].

\section{Results}

\section{Outcomes of characteristics of the included studies}


At the initial steps, 246 studies were found in the four databases. After duplications were removed, 231 papers were retained for reviewing their abstracts and titles. Only nine studies met the eligibility criteria and were included for a full-text review. They also fitted the criteria for systematic review and provided primary (nine studies on the prevalence of obesity and three studies on the risk of hospital admissions) and secondary outcomes (four studies on the risk of ICU admissions and one study on the risk of mortality; (Table 1). Among the nine studies, only four [1], [2] [10], [11] were eligible for meta-analysis (Figure 1). After the quality was assessed, six and three studies were found to have high and moderate qualities (5-9 stars), respectively. All of the four studies that were included in the meta-analysis indicated a high quality of assessment (8-9 stars).

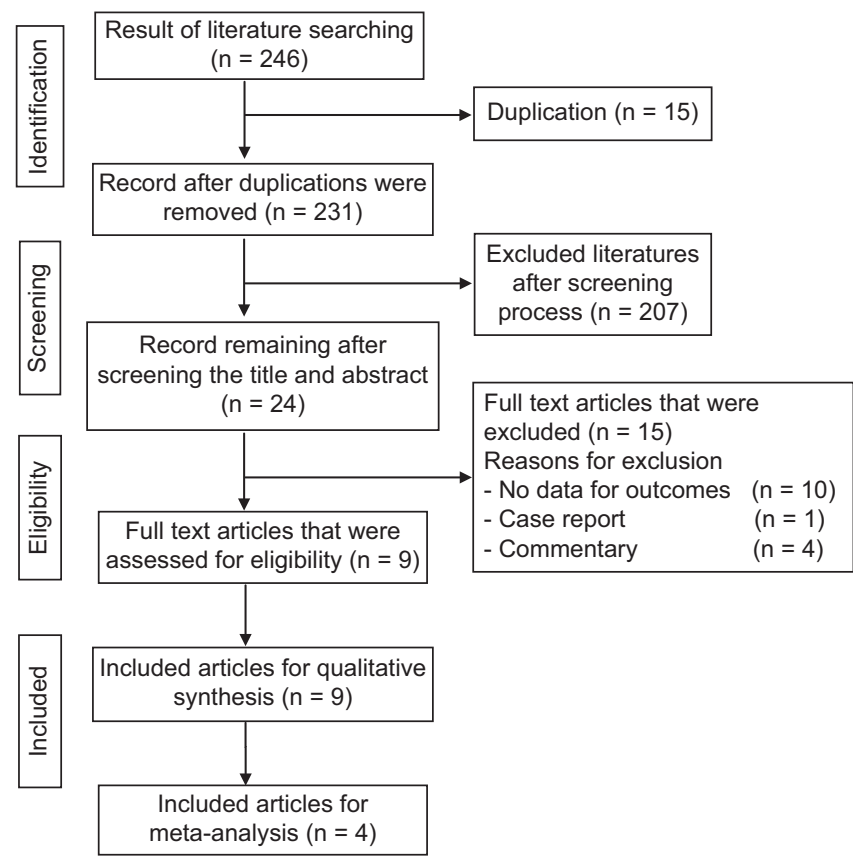

Figure 1: The PRISMA flow chart of the included studies

The total number of patients who had COVID-19 was reported from the nine included studies was 29,776 . The median age was between 52 and 72 years, and males were predominant. Obesity was identified as the second-highest comorbidity among patients with COVID-19 (Table 2). All the studies were from American and European countries. Among the nine studies, two studies did not provide the complete information of the participants with COVID-19 [24].
Relevant data were requested from the researchers of the nine studies for further analysis, but no response was received. For this reason, only the available data in the studies were examined.

\section{Prevalence of obesity}

The prevalence of obesity among patients with COVID-19 was reported between $20.2 \%$ and $47.6 \%$ from the nine studies (Table 2). The five studies provided information on the prevalence of severe obesity among patients with COVID-19 from $13.9 \%$ to $28.2 \%$ (Table 3 ).

The information about the number of patients with obesity and severe obesity among patients with COVID-19 is presented in Table 3. The pooled prevalence of obesity among patients with COVID-19 from the nine studies was $26.1 \%(7,759 / 29,776)$. By comparison, the pooled prevalence of severe obesity among the patients with COVID-19 from the five included studies was $15.5 \%(1,516 / 9,799)$.

\section{Risk of hospital admissions}

The rates of hospital admissions among patients with COVID-19 were between $36.8 \%$ and $100 \%$. Five [2], [3], [9], [24], [25] out of the nine studies showed a hospital admission of $100 \%$ among the patients with COVID-19 because their study participants were mainly hospitalized patients with COVID-19. The total number of the hospitalized patients with COVID-19 was 17,997 from all the nine studies (Table 2).

Only three [1], [10], [11] out of the nine studies provided the information on obesity among the hospitalized patients with COVID-19. Among 9,372 hospitalized patients with COVID-19, 2896 (30.9\%) had obesity. Obesity was the second-highest comorbidity following hypertension. Obesity in patients with COVID- 19 resulted in a significantly increased risk of hospital admission with OR $=1.99(95 \% \mathrm{Cl}=1.12-3.53$, $\left.\mathrm{p}=0.02, \mathrm{Tau}^{2}=0.25, \mathrm{I}^{2}=99 \%\right)$, compared with patients with COVID-19 but without obesity (Figure 2).

Only one study [10] provided data about severe obesity among the patients with COVID-19. A total of $233(17.5 \%)$ and $362(15.8 \%)$ patients with COVID-19 and severe obesity were hospitalized and nonhospitalized, respectively.

Table 1: Studies providing data related to outcomes $(n=9)$

\begin{tabular}{|c|c|c|c|c|c|c|c|c|}
\hline \multirow[t]{2}{*}{ Study } & \multicolumn{2}{|c|}{ Obesity prevalence } & \multicolumn{2}{|c|}{ Hospital admission } & \multicolumn{2}{|c|}{ ICU admission } & \multicolumn{2}{|c|}{ Mortality risk } \\
\hline & $\mathrm{BMI} \geq 30$ & $\mathrm{BMI} \geq 35$ & $\mathrm{BMI} \geq 30$ & $\mathrm{BMI} \geq 35$ & $\mathrm{BMI} \geq 30$ & $\mathrm{BMI} \geq 35$ & $\mathrm{BMI} \geq 30$ & $\mathrm{BMI} \geq 35$ \\
\hline Bello-Chavola et al. [1] & $\mathrm{X}$ & & $\mathrm{X}$ & & $\mathrm{X}$ & & $\mathrm{X}$ & \\
\hline Cummings, et al. [24] & $x$ & $x$ & & & & & & \\
\hline Petrillli, et al. [11] & $x$ & & $x$ & & $x$ & & & \\
\hline McMichael, et al. [25] & $x$ & & & & & & & \\
\hline Garg, et al. [25] & $x$ & & & & & & & \\
\hline Simonnet, et al. [3] & $x$ & $x$ & & & & & & \\
\hline Lighter, et al. [10] & $x$ & $x$ & $x$ & $x$ & $x$ & $x$ & & \\
\hline Richardson, et al. [9] & $x$ & $x$ & & & & & & \\
\hline Kalligeros, et al. [2] & $x$ & $x$ & & & $x$ & $x$ & & \\
\hline
\end{tabular}




\begin{tabular}{|c|c|c|c|c|c|c|c|c|c|c|}
\hline Study or Subgroup & \multicolumn{2}{|c|}{ Hospitalized } & \multicolumn{2}{|c|}{ Non Hospitalized } & Weight & $\begin{array}{c}\text { Odds Ratio } \\
\text { M-H, Random, } 95 \% \mathrm{CI}\end{array}$ & \multicolumn{3}{|c|}{$\begin{array}{c}\text { Odds Ratio } \\
\text { M-H, Random, } 95 \% \mathrm{Cl}\end{array}$} & \\
\hline Bello-Chavola 2020 & 1553 & 6042 & 1662 & 9487 & $33.7 \%$ & $1.63[1.51,1.76]$ & & & - & \\
\hline Lighter 2020 & 547 & 1331 & 823 & 2284 & $33.2 \%$ & $1.24[1.08,1.42]$ & & & 틀 & \\
\hline Petrilli 2020 & 796 & 1999 & 304 & 2104 & $33.1 \%$ & $3.92[3.37,4.56]$ & & & $=$ & \\
\hline Total $(95 \% \mathrm{Cl})$ & & 9372 & & 13875 & $100.0 \%$ & $1.99[1.12,3.53]$ & & & & \\
\hline Total events & 2896 & & 2789 & & & & & & & \\
\hline $\begin{array}{l}\text { Heterogeneity. } \mathrm{Tau}^{2}= \\
\text { Test for overall effect }\end{array}$ & $\begin{array}{l}0.25 ; \mathrm{Ch} \\
\mathrm{z}=2.35\end{array}$ & $\begin{array}{l}2=13 \\
(P=0 .\end{array}$ & $\begin{array}{l}6.23, \mathrm{df}= \\
021\end{array}$ & $(P<0.00$ & $0001 \mathrm{j} ; 1^{2}$ & $=99 \%$ & 0.01 & $\begin{array}{c}0.1 \\
\text { Decreased risk }\end{array}$ & $\begin{array}{c}10 \\
\text { Increased risk }\end{array}$ & 100 \\
\hline
\end{tabular}

Figure 2: Forest plots of studies exploring the risk of hospital admissions among patients with COVID-19 and obesity (BMI $\geq 30$ ). BMI: Body mass index, Cl: Confidence interval.

Table 2: General characteristics of the included studies for systematic review

\begin{tabular}{|c|c|c|c|c|c|c|c|c|c|}
\hline Authors & $\mathrm{N}$ of participants & Median of age & Males $\mathrm{n}(\%)$ & Obesity n (\%) & $\mathrm{DM} n(\%)$ & HT n (\%) & Hospitalization n (\%) & ICU admission $\mathrm{n}(\%)$ & NOS \\
\hline Bello-Chavola, et al. [1] & 15,529 & $\mathrm{NR}^{\mathrm{a}}$ & $8,977(57.8)$ & $3,215(20.7)$ & $2,831(18.2)$ & $3,370(21.7)$ & $6,042(38.9)$ & $676(4.4)$ & High \\
\hline Cummings, et al. [24] & $257^{\mathrm{b}}$ & 62 & $170(66.1)$ & $119(46.3)$ & $92(35.8)$ & $162(63)$ & $1,150(100)$ & $257(22.3)$ & High \\
\hline Petrillli, et al. [11] & 4,103 & 52 & $2072(50.5)$ & $1100(26.8)$ & $614(15)$ & $1235(30.1)$ & $1,999(48.7)$ & $650(15.8)$ & High \\
\hline McMichael, et al. [38] & 167 & 72 & 55 (32.9) & $37(22.2)$ & $38(22.8)$ & $74(44.3)$ & 66 (39.5) & NR & Moderate \\
\hline Garg, et al. [25] & $178^{\mathrm{c}}$ & NR & NR & $73(41)$ & $47(26.4)$ & 79 (44.4) & $1482(100)$ & NR & Moderate \\
\hline Simonnet, et al. [3] & 124 & 60 & $90(72.6)$ & $59(47.6)$ & $28(22.6)$ & $60(48.4)$ & $124(100)$ & $124(100)$ & High \\
\hline Lighter, et al. [10] & 3,615 & NR & NR & $1,370(37.9)$ & NR & NR & $1331(36.8)$ & $431(11.9)$ & High \\
\hline Richardson, et al. [9] & 5,700 & 63 & $3,437(60.3)$ & $1,737(41.7)$ & $1,808(33.8)$ & $3,026(56.6)$ & $5,700(100)$ & $1,281(22.5)$ & Moderate \\
\hline Kalligeros, et al. [2] & 103 & 60 & $63(61.2)$ & $49(47.5)$ & $38(36.8)$ & $66(64.1)$ & $103(100)$ & $44(42.7)$ & High \\
\hline Total & 29,776 & & 14,864 & 7759 & 5496 & 8072 & 17,997 & 3,463 & \\
\hline
\end{tabular}

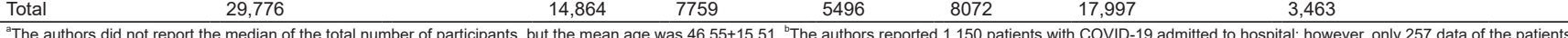
were available. 'The authors reported 1,482 patients with COVID-19 admitted to hospital; however, only 178 data of patients were available. DM: diabetes mellitus, HT: Hypertension, ICU: Intensive care unit, N: Number. were available. The authors reported 1,482 patients with COVID-19 adn

\section{Risk of ICU admissions}

Of the nine studies, seven [1], [2], [3], [9], [10], [11], [24] reported the data about ICU admissions, with a total of 3,463 patients with COVID- 19. Approximately $4.4-100 \%$ patients had COVID-19 and were admitted to the ICU. Simonnet et al. [3] showed that $100 \%$ of the patients with COVID- 19 were admitted to ICU, because all of the study participants were recruited from the ICU (Table 2).

Table 3: Number of patients who had COVID-19 with obesity and severe obesity

\begin{tabular}{|c|c|c|c|c|}
\hline \multirow[t]{2}{*}{ Study } & \multicolumn{2}{|c|}{$\mathrm{BMI} \geq 30$ (obesity) } & \multicolumn{2}{|c|}{ BMI $\geq 35$ (severe obesity) } \\
\hline & $\mathrm{n}(\%)$ & Total patients & $\mathrm{n}(\%)$ & Total patients \\
\hline Bello-Chavola, et al. [1] & $3,215(20.7)$ & 15,529 & - & - \\
\hline Cummings, et al. [24] & $119(46.3)$ & 257 & $68(26.5)$ & 257 \\
\hline Petrillli, et al. [11] & $1,100(26.8)$ & 4,103 & - & - \\
\hline McMichael, et al. [38] & $37(22.2)$ & 167 & - & - \\
\hline Garg, et al. [25] & $73(41.1)$ & 178 & - & - \\
\hline Simonnet, et al. [3] & $59(47.6)$ & 124 & $35(28.2)$ & 124 \\
\hline Lighter, et al. [10] & $1,370(37.9)$ & 3,615 & $595(16.5)$ & 3,615 \\
\hline Richardson, et al. [9] & $1,737(41.7)$ & 5,700 & 791 (13.9) & 5,700 \\
\hline Kalligeros, et al. [2] & $49(47.5)$ & 103 & $27(26.2)$ & 103 \\
\hline Prevalence (\%) & $7,759,26.06 \%$ & 29,776 & $1,516,15.47 \%$ & 9,799 \\
\hline
\end{tabular}

Four studies [1], [2], [10], [11] provided information on patients with COVID-19 and obesity for meta-analysis. Of the 1,801 patients with COVID19 who were admitted to the ICU, 692 had COVID-19 and obesity (38.4\%). Obesity was still the secondhighest comorbidity among COVID-19 patients, following hypertension. The patients with COVID-19 and obesity had a significantly increased risk of ICU admissions with OR $=1.77(95 \% \mathrm{Cl}=1.52-2.06, \mathrm{p}<$ $0.00001, \mathrm{Tau}^{2}=0.01, \mathrm{I}^{2}=45 \%$, Figure 3) compared with that of the patients with COVID-19 but without obesity.

The information on patients who had COVID- 19 and severe obesity and were admitted to the ICU was only available from two studies [2], [10] for meta-analysis. Of 475 patients with COVID- 19 who were admitted to the ICU, 120 had severe obesity (25.3\%). In comparison with patients with COVID-19 but without severe obesity, those with severe obesity had a significantly increased risk of ICU admission (OR 1.79, 95\% Cl 1.42-2.25, $\mathrm{p}<0.00001, \mathrm{Tau}^{2}=0.00, \mathrm{I}^{2}=0 \%$, Figure 4).

\section{Mortality risk}

Only one study [1] provided information about the mortality rate of patients with COVID-19 and obesity but did not have data on severe obesity. Of 14,095 COVID-19 survivors, 2,777 (19.7\%) had obesity. However, of the 1,434 patients who died of COVID- 19, 438 (30.5\%) had obesity.

\section{Meta-regression outcomes}

Meta-regression was applied to explore the high heterogeneity in meta-analysis outcomes. $\mathrm{I}^{2}$ of the risk of hospital admissions among patients with COVID- 19 and obesity patients indicated a high heterogeneity. The CMA, however, could not be utilized for the analysis because of limited number of studies included in meta-regression.

The meta-regression of heterogeneity was conducted to explore the heterogeneity by using the design (retrospective vs. prospective) and location (USA vs. Mexico) as covariates. However, meta- regression was only performed for the design covariate, and it was not doable for location covariate because of the limited numbers of studies $(n=2)$. The outcomes of meta-regression showed $\beta=-0.235$ 


\begin{tabular}{|c|c|c|c|c|c|c|c|c|c|c|}
\hline \multirow[b]{2}{*}{ Study or Subgroup } & \multicolumn{2}{|c|}{ ICU } & \multicolumn{2}{|c|}{ No ICU } & \multirow[b]{2}{*}{ Weight } & \multicolumn{2}{|l|}{ Odds Ratio } & \multirow{2}{*}{\multicolumn{2}{|c|}{$\begin{array}{c}\text { Odds Ratio } \\
\text { M-H, Random, } 95 \% \mathrm{CI}\end{array}$}} & \\
\hline & Events & Total & Events & Total & & M-H, Random, 95\% CI & & & & \\
\hline Bello-Chavola 2020 & 205 & 676 & 3010 & 14853 & $34.3 \%$ & $1.71[1.45,2.03]$ & & & $=$ & \\
\hline Kalligeros 2020 & 25 & 44 & 24 & 59 & $3.5 \%$ & $1.92[0.87,4.23]$ & & & & \\
\hline Lighter 2020 & 202 & 431 & 1168 & 3184 & $29.0 \%$ & $1.52[1.24,1.86]$ & & & $\rightarrow$ & \\
\hline Petrilli 2020 & 260 & 650 & 840 & 3453 & $33.2 \%$ & $2.07[1.74,2.47]$ & & & $=$ & \\
\hline Total $(95 \% \mathrm{Cl})$ & & 1801 & & 21549 & $100.0 \%$ & $1.77[1.52,2.06]$ & & & $\bullet$ & \\
\hline Total events & 692 & & 5042 & & & & & & & \\
\hline $\begin{array}{l}\text { Heterogeneity. } \mathrm{Tau}^{2}= \\
\text { Test for overall effect: }\end{array}$ & $\begin{array}{l}0.01 ; \mathrm{Cr} \\
\mathrm{z}=7.36\end{array}$ & $\begin{array}{l}i^{2}=5.4 \\
(P<0\end{array}$ & $\begin{array}{l}45, \mathrm{df}= \\
.000011\end{array}$ & $3(\mathrm{P}=$ & [4]; $1^{2}=$ & $45 \%$ & 0.01 & $\begin{array}{cc}0.1 & 1 \\
\text { Decreased risk }\end{array}$ & $\begin{array}{c}10 \\
\text { Increased risk }\end{array}$ & 100 \\
\hline
\end{tabular}

Figure 3: Forest plots of studies exploring the risk of ICU admissions among patients with COVID-19 and obese (BMI $\geq 30$ ). BMI: Body mass index, CI: Confidence interval, ICU: Intensive care unit

\begin{tabular}{|c|c|c|c|c|c|c|c|c|c|c|}
\hline Study or Subgroup & \multicolumn{2}{|l|}{ ICU } & \multicolumn{2}{|c|}{ No ICU } & Weight & $\begin{array}{c}\text { Odds Ratio } \\
\text { M-H, Random, } 95 \% \mathrm{CI}\end{array}$ & \multicolumn{4}{|c|}{$\begin{array}{c}\text { Odds Ratio } \\
\text { M-H, Random, } 95 \% \mathrm{Cl}\end{array}$} \\
\hline Kalligeros 2020 & 14 & 44 & 13 & 59 & $6.8 \%$ & $1.65[0.68,4.00]$ & & 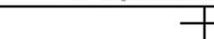 & & \\
\hline Lighter 2020 & 106 & 431 & 489 & 3184 & $93.2 \%$ & $1.80[1.41,2.28]$ & & & & \\
\hline Total $(95 \% \mathrm{CI})$ & & 475 & & 3243 & $100.0 \%$ & $1.79[1.42,2.25]$ & & & 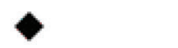 & \\
\hline Total events & 120 & & 502 & & & & & & & \\
\hline $\begin{array}{l}\text { Heterogeneity. } \mathrm{Tau}^{2}= \\
\text { Test for owerall effect }\end{array}$ & $\begin{array}{l}0.00 ; \mathrm{Chi} \\
\mathrm{Z}=4.92\end{array}$ & $\begin{array}{l}\mathrm{i}^{2}=0 . \\
(\mathrm{P}<0\end{array}$ & $\begin{array}{l}03, \mathrm{df}= \\
.00001 \mathrm{j}\end{array}$ & $1(\mathrm{P}=\mathrm{C}$ & $0.86 \mathrm{j} ; \mathrm{l}^{2}$ & $=0 \%$ & 0.01 & $\begin{array}{c}0.1 \\
\text { Decreased risk }\end{array}$ & $\begin{array}{c}10 \\
\text { Increased risk }\end{array}$ & 100 \\
\hline
\end{tabular}

Figure 4: Forest plots of studies exploring the risk of ICU admissions among patients with COVID-19 and severe obese (BMI $\geq 35$ ). BMI: Body mass index, Cl: Confidence interval, ICU: Intensive care unit

and standard error $=0.110(\mathrm{Q}=4.53, \mathrm{df}=1,95 \%$ $\mathrm{Cl}=-0.452$ to $-0.018, \mathrm{p}=0.034) ;$ the goodness-offit outcomes were $\operatorname{Tau}^{2}=0.000$, Tau $=0.000$, and $I^{2}=0 \%$ $(\mathrm{Q}=0.92, \mathrm{df}=2, \mathrm{p}=0.631)$, and the proportions of variances were $\mathrm{Tau}^{2}=0.0101$, Tau $=0.1007, \mathrm{I}^{2}=44.9 \%$, and $R^{2}$ analog $=1(Q=5.45, d f=3, p=0.142)$. These results indicated that the covariate of the retrospective design significantly contributed to a decrease of 0.235 units in the risk of ICU admissions among patients with COVID- 19 and obesity.

\section{Bias assessment}

The funnel plots indicated a symmetrical shape and a non-higher concentration at the bottom of the funnel plots (Additional file: Figure S1-3). Furthermore, Egger's regression yielded intercept $=9.845,95 \%$ $\mathrm{Cl}=-248.312$ to $268.001, \mathrm{df}=1, \mathrm{p}=0.713$ for hospital admission and intercept $=-0.067,95 \% \mathrm{Cl}-9.022$ to -9.067 , $d f=2, p=0.977$ for ICU admissions among patients with obesity. These findings showed that the funnel plot had no asymmetry. The analysis on the publication bias of the risk of ICU admissions among patients with severe obesity was inapplicable because a minimum of three studies was not achieved.

\section{Discussion}

This study addressed the prevalence, risk of hospital and ICU admissions, and risk of mortality among patients with COVID-19, obesity, and severe obesity using available published data. To our best knowledge, this study was the first to extensively perform a systematic review and meta-analysis and address the aforementioned questions, particularly for severe obesity. Our findings revealed that $26.1 \%$ and $15.5 \%$ of patients with COVID-19 had obesity and severe obesity, respectively. The risk of hospital and ICU admissions of the patients with COVID-19 and obesity was twice higher that of the patients without obesity. Furthermore, COVID-19 patients with severe obesity had almost twice risks of ICU admission than non-severe obese COVID-19 patients.

The previous studies had limitations on the regional report and some reported small cases of COVID-19. The current study presented a pooled data of obesity and severe obesity on COVID-19 patients. The previous study showed a pooled prevalence of obesity was about $33.9 \%$, relatively higher than these findings [26]. Furthermore, obesity was identified as the second-highest prevalence of comorbidity among COVID- 19, particularly in American and European countries. This finding was different from previous results that highlighted diabetes as the second- largest comorbidity among patients with COVID- 19 [16], [27], [28], [29]. The previous studies rarely assessed obesity among patients with COVID-19. Thus, this finding might reflect the basic characteristics of the population [16], especially in areas with a high prevalence of obesity.

Obesity and severe obesity in patients with COVID-19 were associated with poor outcomes, namely, hospital admission, ICU admission, and mortality. The current meta-analyses indicated that patients with COVID-19 and obesity had almost twice 
the risk of hospital admissions. These results were in accordance with other meta-analysis, in which identified the OR about 1.3-2.3 [30], [31], [32]. Obesity and severe obesity significantly increased the risk of ICU admissions among patients with COVID-19 with moderate heterogeneity, by $77 \%$ and $79 \%$, respectively. The outcome of twice risks of ICU admissions among patients with COVID- 19 and obesity was similar with the previous meta-analysis (OR 1.3-2.3) [30], [31], [32]. BMI $\geq 30$ and a history of heart diseases are independently associated with the use of invasive mechanical ventilation [2], [31], [32]. The mechanism of obesity contributing to the severity level of COVID- 19 is recommended [2]. Obesity caused multistranded pathophysiology, such as hyperactivation, increased interleukin-6 (IL-6) concentration, inflammation, and presence of other comorbidities [33]. Abdominal obesity leads to impaired lung ventilation and reduced oxygen saturation [7], [34]. A study on pulmonary function has shown that patients with obesity have restrictive and decreased lung volumes [35]. Some studies have indicated that patients with COVID-19 and severe obesity are subjected to long-term invasive mechanical ventilation [3], [7].

Obesity is associated with increased IL-6 [7], [33] and C-reactive protein contents [7]. Any abnormal secretion of interferon, adipokines, and cytokines (i.e. tumor necrotic factor alpha) result in a chronic low-grade inflammation. This condition potentially impairs the immune system by dysregulating the expression of tissue leukocyte [3], [7], [36]. Obesity and metabolic syndrome increase type 2 inflammation that impacts the lung parenchyma and bronchi [37], [38]. Obesity can stimulate insulin resistance and decrease beta-cell function. Consequently, insulin must be administered during a severe infection, thereby impairing host defense and leading to immunological deficit. In addition, obesity exacerbates the thrombosis that corresponds to prothrombotic disseminated intravascular coagulopathy and venous thromboembolism in patients with COVID- 19 [7].

The heterogeneity outcome of the risk of hospital admissions of patients with COVID-19 and obesity was high. Furthermore, meta-regression could not be performed to explore heterogeneity because of the limited number of studies included for analysis [20]. We acknowledged that the unexplained heterogeneity of these results might affect the inconsistency across the studies [22], [23]. Thus, further studies on hospital admissions among patients with COVID-19 and obesity should be performed to investigate such inconsistencies. Only Lighter et al. [10] reported the data about the risk of hospitalization among patients with COVID-19 and severe obese, with $\mathrm{OR}=2.2(95 \% \mathrm{Cl}=1.7-2.9$, $\mathrm{p}<0.0001)$. Another study has identified that BMI $>40$ contributes to 6.2 times $(95 \% \mathrm{Cl}=4.2-9.3)$ of the hospitalization risk [11]. The retrospective design covariate significantly helped decrease the risk of ICU admissions among the patients with COVID- 19 and obesity by 0.235 units. The covariate of the retrospective design resulted in $\mathrm{R}^{2}$ analog $=1$, which indicated that the covariate of the retrospective design could explain all variances [20].

\section{Strength and limitation of the study}

This systematic review and meta-analysis had several limitations related to the nature of the study. The studies for meta-analysis were limited, although the nine included studies considered of a large number of patients with obesity or severe obesity as participants. The risk of hospital and ICU admissions among patients with COVID-19 and obesity might be underestimated because the accessibilities of hospital beds or ICU units are restricted. The high heterogeneity on the risk of hospital admission among patients with COVID-19 and obesity is also unexplained. Subgroup analysis is not workable because of the limited data and numbers of included studies. Furthermore, this study did not identify the risk of hospital admissions among patients with COVID-19 severe obesity because of limited data. Few studies have provided data about the survivorship of patients with COVID-19 and obesity or severe obesity. Thus, future research related to the survivorship of these patients should be conducted.

\section{Conclusion}

This systematic review identified that the prevalence rates of obesity and severe obesity were $26 \%$ and $15 \%$ among patients with COVID-19, respectively. Patients with COVID-19 and obesity had twice the risks of hospital and ICU admissions compared with those of patients with COVID-19 but without obesity. Remarkably, patients with COVID-19 and severe obesity also showed approximately twice the risks for ICU admission compared with those of patients with COVID-19. Populations and health-care providers should notice and be aware of the high risk of hospital and ICU admissions among patients with COVID-19, obesity, and severe obesity.

This review provides valuable information on the high risk of hospital and ICU admissions for patients with COVID-19, obesity, and severe obesity. Healthcare providers should intensively monitor the health outcomes these groups of patient. In addition, patients with obesity or severe obesity and their families should be aware of their risks of the severity of COVID-19 and minimize contact with other patients with COVID- 19. Health-care providers should also provide valid education on COVID-19 prevention and raise the awareness related to a high risk among patients with COVID-19 and obesity or severe obesity. 


\section{Supplementary Information}

Additional file 1: Supplementary methods, PRISMA checklist. Figure S1, Funnel plots of the included studies on the risk of hospital admissions among patients with COVID-19 and obesity. Figure S2, Funnel plots of the included studies on the risk of ICU admissions among patients with COVID-19 and obesity. Figure S3, Funnel plots of the included studies on the risk of ICU admissions among patients with COVID-19 and severe obesity.

\section{References}

1. Bello-Chavolla OY. Bahena-López JP, Antonio-Villa NE, Vargas- Vázquez A, Gonzá lez-Dıaz A, Márquez-Salinas A, et al. Predicting mortality due to SARS-CoV-2: A mechanistic score relating obesity and diabetes to COVID-19 outcomes in Mexico. J Clin Endocrinol Metab. 2020;105(8):dgaa346. https:// doi.org/10.1101/2020.04.20.20072223

PMid:32474598

2. Kalligeros M, Shehadeh F, Mylona EK, Benitez G, Beckwith CG, Chan PA, Mylonakis E. Association of obesity with disease severity among patients with Coronavirus disease 2019. Obesity (Silver Spring). 2020;28(7):1200-4. https://doi.org/10.1002/ oby.22859

PMid:32352637

3. Simonnet A, Chetboun M, Poissy J, Raverdy V, Noulette J, Duhamel A, et al. High prevalence of obesity in severe acute respiratory syndrome Coronavirus-2 (SARS-CoV-2) requiring invasive mechanical ventilation. Obesity. 2020;28(7):1195-9. https://doi.org/10.1002/oby.22831

PMid:32271993

4. Li Q, Guan X, Wu P, Wang X, Zhou L, Tong Y, et al. Early transmission dynamics in Wuhan, China, of novel coronavirusinfected pneumonia. N Engl J Med. 2020;382(13):1199-207. PMid:31995857

5. Grasselli G, Zangrillo A, Zanella A, Antonelli M, Cabrini L, Castelli A, et al. Baseline characteristics and outcomes of 1591 patients infected with SARS-CoV-2 admitted to ICUs of the Lombardy region, Italy. JAMA. 2020;323(16):1574-81. PMid:32250385

6. Bhatraju PK, Ghassemieh BJ, Nichols M, Kim R, Jerome KR, Nalla AK, Greninger AL, Pipavath S, Wurfel MM, Evans L, Kritek PA. COVID-19 in critically ill patients in the Seattle regioncase series. N Engl J Med. 2020;382(21):2012-22. https://doi. org/10.1056/nejmoa2004500

PMid:32227758

7. Sattar N, Mclnnes IB, McMurray JJ. Obesity is a risk factor for severe COVID-19 infection: Multiple potential mechanisms. Circulation. 2020;142(1):4-6. https://doi.org/10.1161/ circulationaha.120.047659

PMid:32320270

8. Zheng KI, Gao F, Wang XB, Sun QF, Pan KH, Wang TY, et al. Letter to the editor: Obesity as a risk factor for greater severity of COVID-19 in patients with metabolic associated fatty liver disease. Metabolism. 2020;108:154244. https://doi. org/10.1016/j.metabol.2020.154244

PMid:32320741
9. Richardson S, Hirsch JS, Narasimhan M, Crawford JM, McGinn T, Davidson KW, et al. Presenting characteristics, comorbidities, and outcomes among 5700 patients hospitalized with COVID- 19 in the New York City area. JAMA. 2020;323(20):2052-9. https://doi.org/10.1001/jama.2020.6775 PMid:32320003

10. Lighter J, Phillips M, Hochman S, Sterling S, Johnson D, Francois $\mathrm{F}$, et al. Obesity in patients younger than 60 years is a risk factor for COVID-19 hospital admission. Clin Infect Dis. 2020;71(15):896-7. https://doi.org/10.1093/cid/ciaa415 PMid:32271368

11. Petrilli CM, Jones SA, Yang J. Factors associated with hospital admission and critical illness among 5279 patients with Coronavirus disease 2019 in New York city prospective cohort study. BMJ. 2020;369:m1966. https://doi.org/10.1136/ bmj.m1966 PMid:32444366

12. Jose RJ, Manuel A. Does Coronavirus disease 2019 disprove the obesity paradox in acute respiratory distress syndrome? Obesity (Silver Spring). 2020;28(6):1007. https://doi. org/10.1002/oby.22835

PMid:32294322

13. Dietz W, Santos-Burgoa C. Obesity and its implications for COVID-19 mortality. Obesity (Silver Spring). 2020;28(6):1005 PMid:32237206

14. Moher D, Liberati A, Tetzlaff J, Altman DG. Preferred reporting items for systematic reviews and meta-analyses: The PRISMA statement. Int J Surg. 2010;8(5):336-41. https://doi. org/10.1016/j.ijsu.2010.02.007 PMid:20171303

15. Wells GA, Shea B, O'connell D, Peterson J, Welch V, Losos M, Tugwell P. The Newcastle-Ottawa Scale (NOS) for Assessing the Quality if Nonrandomized Studies in Meta-Analyses. Ottawa Hospital Research Institute. Clinical Epidemiology; 2016. Available from: http://www.ohri.ca/ programs/clinical_epidemiology/oxford.asp. [Last accessed on 2020 Aug 13].

16. Roncon L, Zuin M, Rigatelli G, Zuliani G. Diabetic patients with COVID-19 infection are at higher risk of ICU admission and poor short-term outcome. J Clin Virol. 2020;127:104354. https://doi. org/10.1016/j.jcv.2020.104354

PMid:32305882

17. Borenstein M. Software for publication bias. In: Rothstein HR, Sutton AJ, Borenstein $M$, editors. Publication Bias in Meta- Analysis: Prevention, Assessment and Adjustments. England: John Wiley and Sons; 2005. https://doi. org/10.1002/0470870168

18. Egger $M$, Smith GD, Schneider $M$, Minder $C$. Bias in meta-analysis detected by a simple, graphical test. BMJ. 1997;315(7109):629-34. https://doi.org/10.1136/ bmj.315.7109.629

PMid:9310563

19. Collaboration C. Review Manager (RevMan) [computer program] Version 5.2. 3, The Nordic Cochrane Centre, Copenhagen, 2012. Health Psychol Rev. 2014;17.

20. Borenstein M, Hedges LV, Higgins JP, Rothstein HR. Comprehensive Meta-Analysis. $2^{\text {nd }}$ ed. United Kindom: Biostat; 2009.

21. Huedo-Medina TB, Sánchez-Meca J, Marín-Martínez F, Botella J. Assessing heterogeneity in meta-analysis: $Q$ statistic or $\mathrm{I}^{2}$ index?. Psychol Methods. 2006;11(2):193-206. https://doi. org/10.1037/1082-989x.11.2.193 PMid: 16784338

22. Higgins JP, Thompson SG, Deeks JJ, Altman DG. Measuring inconsistency in meta-analyses. BMJ. 2003;327(7414):557-60. 
https://doi.org/10.1136/bmj.327.7414.557

PMid: 12958120

23. Thompson SG, Higgins JP. How should meta-regression analyses be undertaken and interpreted? Stat Med. 2002;21(11):1559-73. https://doi.org/10.1002/sim.1187

PMid: 12111920

24. Cummings MJ, Baldwin MR, Abrams D, Jacobson SD, Meyer BJ, Balough EM, et al. Epidemiology, clinical course, and outcomes of critically ill adults with COVID-19 in New York City: A prospective cohort study. Lancet. 2020;395(10239):1763-70. https://doi.org/10.1016/s0140-6736(20)31189-2 PMid:32442528

25. Garg S, Kim L, Whitaker M, O'Halloran A, Cummings C Holstein R, et al. Hospitalization rates and characteristics of patients hospitalized with laboratory-confirmed Coronavirus disease 2019-COVID-NET, 14 States, March 1-30, 2020. MMWR Morb Mortal Wkly Rep. 2020;69(15):458-64. https://doi. org/10.15585/mmwr.mm6915e3 PMid:32298251

26. Malik P, Patel U, Patel K, Martin M, Shah C, Mehta D, Malik FA, Sharma A. Obesity a predictor of outcomes of COVID-19 hospitalized patients-a systematic review and meta-analysis. J Med Virol. 2021;93(2):1188-93. https://doi.org/10.1002/ jmv.26555

PMid:32975814

27. Hill MA, Mantzoros C, Sowers JR. Commentary: COVID-19 in patients with diabetes. Metabolism. 2020;107:154217. https:// doi.org/10.1016/j.metabol.2020.154217

PMid:32220611

28. Wicaksana AL, Hertanti NS, Ferdiana A, Pramono RB. Diabetes management and specific considerations for patients with diabetes during coronavirus diseases pandemic: A scoping review. Diabetes Metab Syndr. 2020;14(5):1109-20. https://doi. org/10.1016/j.dsx.2020.06.070 PMid:32659694

29. Karyono DR, WicaksanaAL. Current prevalence, characteristics, and comorbidities of patients with COVID-19 in Indonesia. J Community Empowerment Health. 2020;3(2):77-84. https:// doi.org/10.22146/jcoemph.57325

30. Huang $Y$, Lu $Y$, Huang $Y M$, Wang $M$, Ling $W$, Sui $Y$, et al. Obesity in patients with COVID-19: A systematic review and meta-analysis. Metabolism. 2020;28:154378. https://doi. org/10.1016/j.metabol.2020.154378

PMid:33002478

31. Helvaci N, Eyupoglu ND, Karabulut E, Yildiz BO. Prevalence of obesity and its impact on outcome in patients with COVID- 19 A systematic review and meta-analysis. Front Endocrinol (Lausanne). 2021;12:598249. https://doi.org/10.3389/ fendo.2021.598249

PMid:33716962

32. Zhang X, Lewis AM, Moley JR, Brestoff JR. A systematic review and meta-analysis of obesity and COVID-19 outcomes. Sci Rep. 2021;11(1):7193. https://doi.org/10.1038/ s41598-021-86694-1

PMid:33785830

33. Watanabe M, Risi R, Tuccinardi D, Baquero CJ, Manfrini $S$, Gnessi L. Obesity and SARS-CoV-2: A population to safeguard. Diabetes Metab Res Rev. 2020;36(7):e3325. https://doi. org/10.1002/dmrr.3325 PMid:32314503

34. Dixon $A E$, Peters $U$. The effect of obesity on lung function Expert Rev Respir Med. 2018;12(9):755-67. PMid:30056777

35. Watson RA, Pride NB, Thomas EL, Fitzpatrick J, Durighel G, McCarthy $\mathrm{J}$, et al. Reduction of total lung capacity in obese men: Comparison of total intrathoracic and gas volumes. J Appl Physiol. 2010;108(6):1605-12. https://doi.org/10.1152/ japplphysiol.01267.2009 PMid:20299612

36. Huttunen R, Syrjänen J. Obesity and the risk and outcome of infection. Int J Obes (Lond). 2013;37(3):333-40. PMid:22546772

37. Zhang X, Zheng J, Zhang L, Liu Y, Chen GP, Wang L, et al. Systemic inflammation mediates the detrimental effects of obesity on asthma control. Allergy Asthma Proc. 2018;39(1):43- 50. https://doi.org/10.2500/aap.2018.39.4096

PMid:29279059

38. McMichael TM, Currie DW, Clark S, Pogosjans S, Kay M, Schwartz NG, et al. Epidemiology of COVID-19 in a longterm care facility in King County, Washington. N Engl J Med. 2020;382(21):2005-11.

PMid:32220208 


\section{Supplementary}

\section{Table of Contents}

\begin{tabular}{lc}
\hline Supplementary Methods: PRISMA checklist & 3 \\
\hline Figure S1: Funnel plots of the included studies on the risk of hospital & \\
admissions among patients with COVID-19 and obesity & 6 \\
$\begin{array}{l}\text { Figure S2: Funnel plots of the included studies on the risk of ICU } \\
\text { admissions among patients with COVID-19 and obesity }\end{array}$ & 7 \\
$\begin{array}{l}\text { Figure S3: Funnel plots of the included studies on the risk of ICU } \\
\text { admissions among patients with COVID-19 and severe obesity }\end{array}$ & 8 \\
\hline
\end{tabular}

\section{Supplementary Methods: PRISMA checklist}

\begin{tabular}{|c|c|c|c|}
\hline Section/topic & $\#$ & Checklist item & Reported on page \# \\
\hline \multicolumn{4}{|r|}{ Reported on page \# } \\
\hline Title & 1 & $\begin{array}{l}\text { Identify the report as a systematic review, meta-analysis, or both. } \\
\text { ABSTRACT }\end{array}$ & 1 \\
\hline Structured summary & 2 & $\begin{array}{l}\text { Provide a structured summary including, as applicable: background; objectives; data sources; study eligibility criteria, } \\
\text { participants, and interventions; study appraisal and synthesis methods; results; limitations; conclusions and implications of key } \\
\text { findings; systematic review registration number. } \\
\text { INTRODUCTION }\end{array}$ & 1 \\
\hline Rationale & 3 & Describe the rationale for the review in the context of what is already known. & 2 \\
\hline Objectives & 4 & $\begin{array}{l}\text { Provide an explicit statement of questions being addressed with reference to participants, interventions, comparisons, } \\
\text { outcomes, and study design (PICOS). }\end{array}$ & 3 \\
\hline Protocol and registration & 5 & $\begin{array}{l}\text { Indicate if a review protocol exists, if and where it can be accessed (e.g., Web address), and, if available, provide registration } \\
\text { information including registration number. }\end{array}$ & N/A \\
\hline Eligibility criteria & 6 & $\begin{array}{l}\text { Specify study characteristics (e.g., PICOS, length of follow-up) and report characteristics (e.g., years considered, language, } \\
\text { publication status) used as criteria for eligibility, giving rationale. }\end{array}$ & 3 \\
\hline Information sources & 7 & $\begin{array}{l}\text { Describe all information sources (e.g., databases with dates of coverage, contact with study authors to identify additional } \\
\text { studies) in the search and date last searched. }\end{array}$ & 4 \\
\hline Search & 8 & Present full electronic search strategy for at least one database, including any limits used, such that it could be repeated. & 4 \\
\hline Study selection & 9 & $\begin{array}{l}\text { State the process for selecting studies (i.e., screening, eligibility, included in systematic review, and, if applicable, included in the } \\
\text { meta-analysis). }\end{array}$ & 3-4 \\
\hline Data collection process & 10 & $\begin{array}{l}\text { Describe method of data extraction from reports (e.g., piloted forms, independently, in duplicate) and any processes for } \\
\text { obtaining and confirming data from investigators. }\end{array}$ & 4 \\
\hline Data items & 11 & $\begin{array}{l}\text { List and define all variables for which data were sought (e.g., PICOS, funding sources) and any assumptions and simplifications } \\
\text { made. }\end{array}$ & $3-4$ \\
\hline $\begin{array}{l}\text { Risk of bias in individual } \\
\text { studies }\end{array}$ & 12 & $\begin{array}{l}\text { Describe methods used for assessing risk of bias of individual studies (including specification of whether this was done at the } \\
\text { study or outcome level), and how this information is to be used in any data synthesis. }\end{array}$ & 4 \\
\hline Summary measures & 13 & State the principal summary measures (e.g., risk ratio, difference in means). & 5 \\
\hline Synthesis of results & 14 & $\begin{array}{l}\left.\text { Describe the methods of handling data and combining results of studies, if done, including measures of consistency (e.g., } I^{2}\right) \text { for } \\
\text { each meta-analysis. }\end{array}$ & 5 \\
\hline Section/topic & \# & Checklist item & Reported on page \# \\
\hline Risk of bias across studies & 15 & $\begin{array}{l}\text { Specify any assessment of risk of bias that may affect the cumulative evidence (e.g., publication bias, selective reporting within } \\
\text { studies). }\end{array}$ & 5 \\
\hline Additional analyses & 16 & $\begin{array}{l}\text { Describe methods of additional analyses (e.g., sensitivity or subgroup analyses, meta-regression), if done, indicating which } \\
\text { were pre-specified. }\end{array}$ & 5 \\
\hline & & RESULTS & \\
\hline Study selection & 17 & $\begin{array}{l}\text { Give numbers of studies screened, assessed for eligibility, and included in the review, with reasons for exclusions at each stage, } \\
\text { ideally with a flow diagram. }\end{array}$ & $5-6,20$ \\
\hline Study characteristics & 18 & $\begin{array}{l}\text { For each study, present characteristics for which data were extracted (e.g., study size, PICOS, follow-up period) and provide the } \\
\text { citations. }\end{array}$ & $5-6,18$ \\
\hline Risk of bias within studies & 19 & Present data on risk of bias of each study and, if available, any outcome level assessment (see item 12). & 9 \\
\hline $\begin{array}{l}\text { Results of individual } \\
\text { studies }\end{array}$ & 20 & $\begin{array}{l}\text { For all outcomes considered (benefits or harms), present, for each study: (a) simple summary data for each intervention } \\
\text { group (b) effect estimates and confidence intervals, ideally with a forest plot. }\end{array}$ & $6-8$ \\
\hline Additional analysis & 23 & $\begin{array}{l}\text { Give results of additional analyses, if done (e.g., sensitivity or subgroup analyses, meta-regression [see Item 16]). } \\
\text { DISCUSSION }\end{array}$ & $8-9$ \\
\hline Summary of evidence & 24 & $\begin{array}{l}\text { Summarize the main findings including the strength of evidence for each main outcome; consider their relevance to key } \\
\text { groups (e.g., healthcare providers, users, and policy makers). }\end{array}$ & 9-11 \\
\hline Limitations & 25 & $\begin{array}{l}\text { Discuss limitations at study and outcome level (e.g., risk of bias), and at review-level (e.g., incomplete retrieval of identified } \\
\text { research, reporting bias). }\end{array}$ & $11-12$ \\
\hline Conclusions & 26 & $\begin{array}{l}\text { Provide a general interpretation of the results in the context of other evidence, and implications for future research. } \\
\text { FUNDING }\end{array}$ & 12 \\
\hline Funding & 27 & $\begin{array}{l}\text { Describe sources of funding for the systematic review and other support (e.g., supply of data); role of funders for the systematic } \\
\text { review. }\end{array}$ & Title page \#2 \\
\hline
\end{tabular}



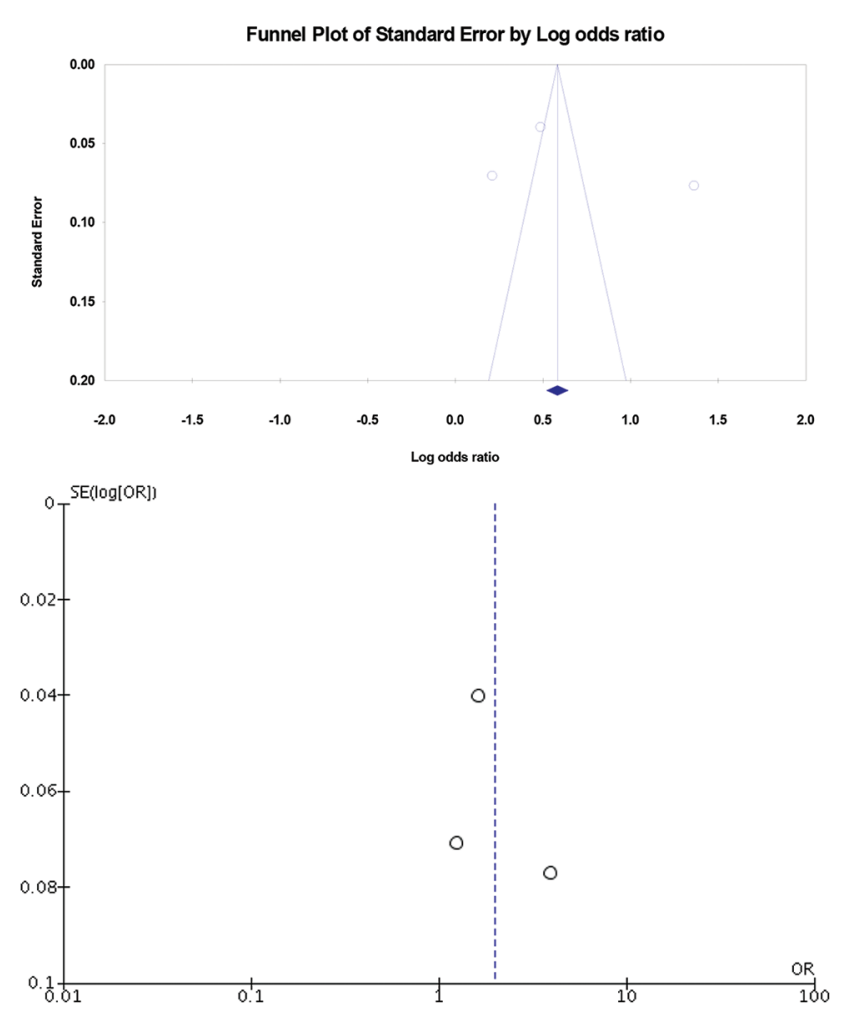

Figure S1: Funnel plots of the included studies on the risk of hospital admissions among patients with COVID-19 and obesity
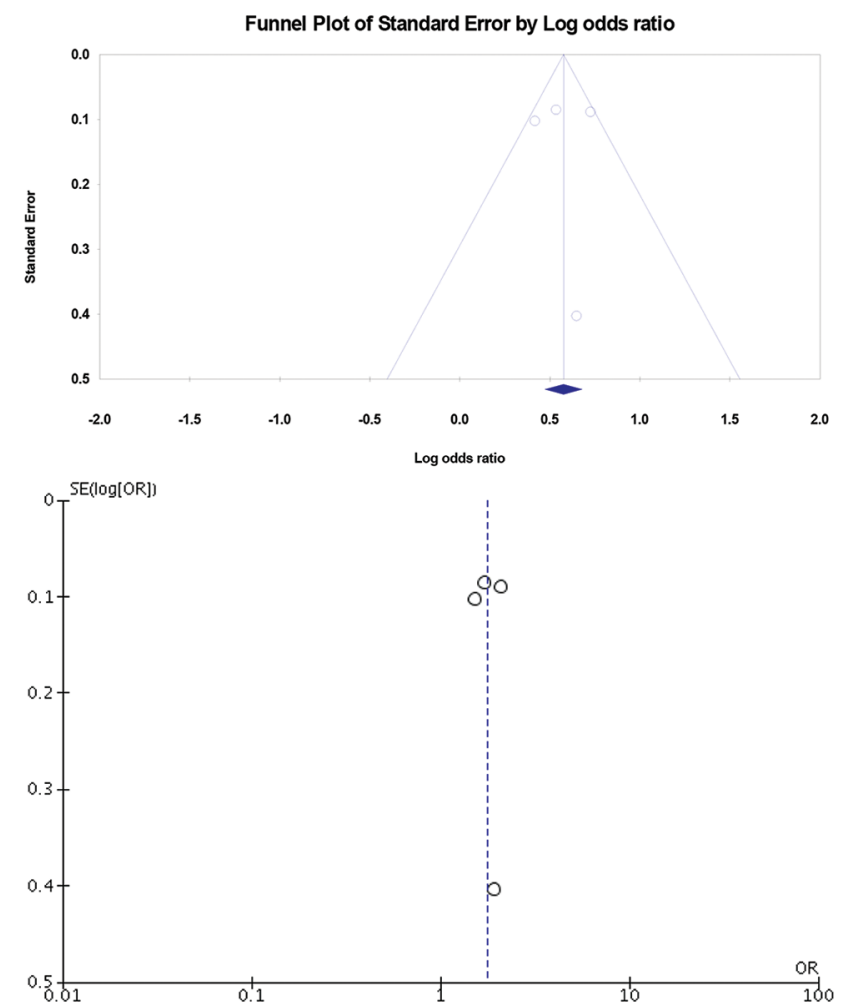

Figure S2: Funnel plots of the included studies on the risk of ICU admissions among patients with COVID-19 and obesity

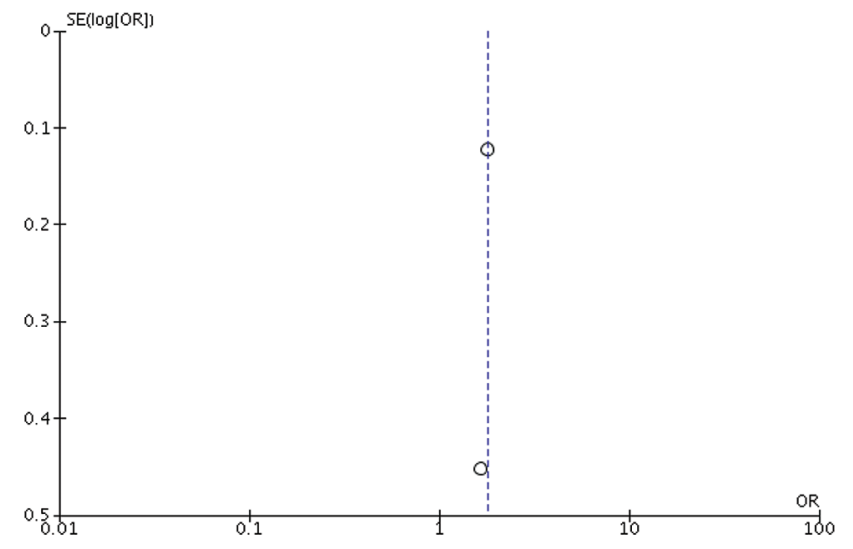

Figure S3: Funnel plots of the included studies on the risk of ICU admissions among patients with COVID-19 and severe obesity 